\title{
How do you choose a book for a pre-arrival shared reading scheme within a University? A case study
}

\author{
Alison Baverstock \\ Jackie Steinitz \\ Laura Bryars \\ Kimberley Sheehan \\ Charlotte Butler \\ Allison Williams \\ Angelika Dalba \\ Dan Brixey \\ Adam Conor \\ Ciara Higgins \\ Elle Waddington
}

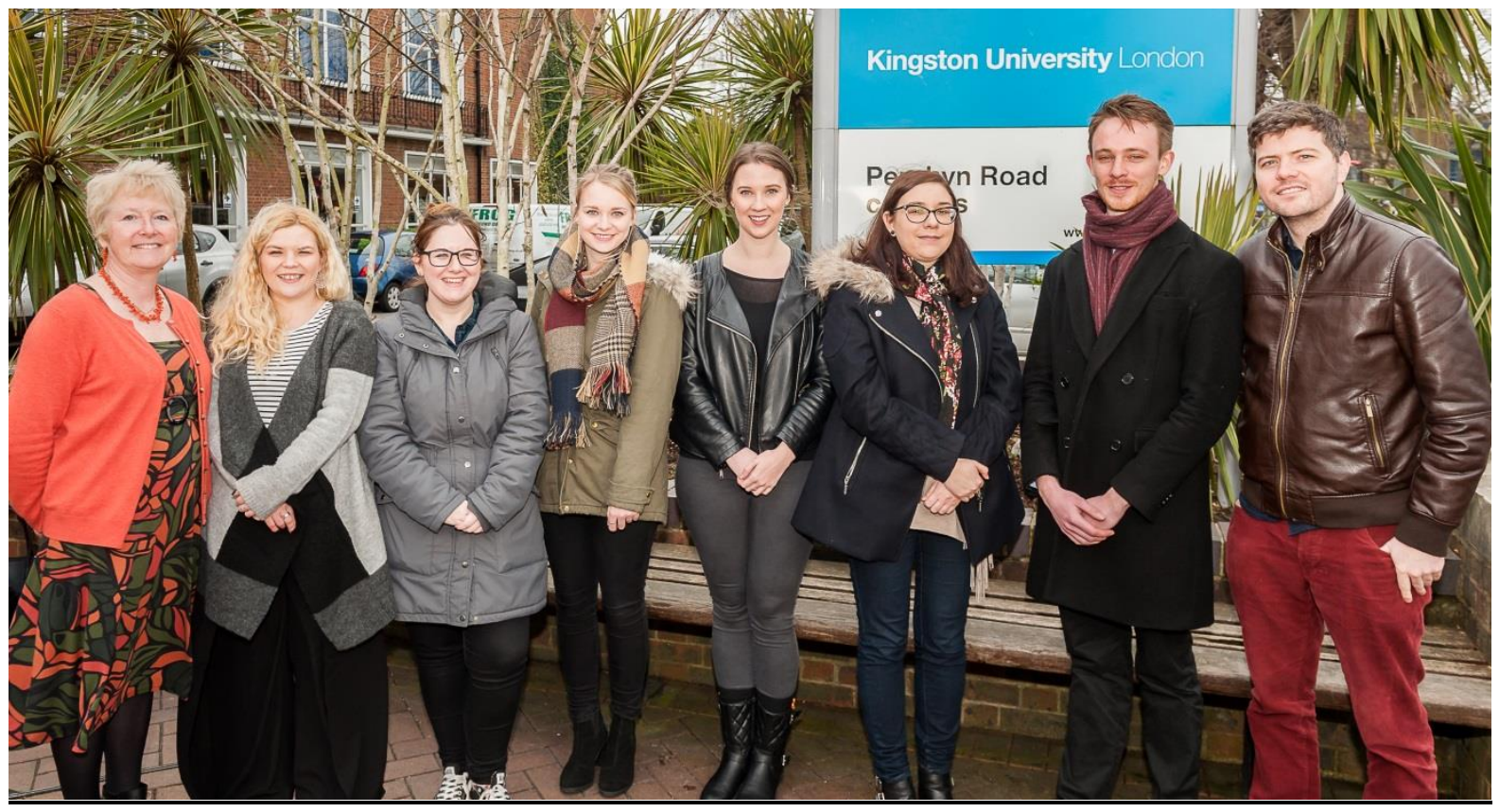

Image 1: Photograph caption, left to right: Alison Baverstock; Laura Bryars; Kimberley Sheehan; Charlotte Butler; Allison Williams; Angelika Dalba; Dan Brixey; Adam Conor. Not pictured: Jackie Steinitz; Ciara Higgins; Elle Waddington.

\section{Abstract}

This paper continues exploration of Kingston University's pre-arrival shared reading scheme, The KU Big Read (KUBR), this time considering action research into how best to choose a common book. After a review of methods used to choose books both specifically in American universities and generally within large shared reading groups, the method used for the KUBR is described. A key objective of the KUBR is to promote inclusion, so the long-list of titles for consideration was produced by inviting the entire community to submit suggestions. Since the list was extensive, time to make a choice was short and there was a strong desire for the methodology to be as objective as possible, it was decided to identify the key criteria relevant for choosing a suitable book then use a simple algorithm - essentially a weighted scoring system - to score each book using readily-available 
data in order to establish a short-list of six books. These were then read by a panel of students, administrative and academic staff and the book finally chosen was Matt Haig's The Humans. This paper details each step of the method and finishes with an appraisal and learnings for next time.

\section{Introduction}

Kingston University established a pre-arrival shared reading scheme in 2015. Prior research into the leisure habits of first-year students, the part played by reading for pleasure, and their anticipated responses to receiving a book before arriving at their university had indicated a likely positive response (Baverstock et al, 2016) and having made the decision to proceed, Nick Hornby's About a boy was chosen by University Vice Chancellor Professor Julius Weinberg as the first title to be shared. This seemed a suitable choice as it was considered a 'good read', was written by a Kingston alumnus (Hornby completed his PGCE at Kingston in 1981), featured city living, was not an offputting title in length or size, and finally 'growing up' was one of the book's central themes - which related well to students approaching transition to university. 10,000 copies of a bespoke edition were printed; one for each of the students about to start at Kingston University and enough for an estimated percentage of interested staff to join in too.

All UK students were sent a copy of the book to their home address, and responses on social media quickly referenced their satisfaction at receiving a 'present' or a 'gift' and feeling 'welcomed', 'included' and 'comforted'. The special Kingston branding of the book received particularly positive comment, and many students concluded that Kingston had its own publishing house. The events given by Hornby in connection with the scheme were packed; after the talk he gave during the first week of term he signed copies of his book for over an hour. The book was included within welcome activities, early weeks' teaching and formative assessment. What was less expected, as it had not been researched, was the response of staff. Books were made available to them ahead of the summer holiday. In addition to copies being much more widely sought than anticipated (so much so that the book had to be twice reprinted) the book was used in a variety of different circumstances as the basis for team-building by both University Finance and Estates Departments, by HR within induction briefings for new staff, and as an promotional or introductory gift by the University's Development and Alumni Relations teams.

When students and staff were surveyed, after the events had finished, it emerged that the scheme had received high levels of discussion within both groups, often with multiple categories of individual (e.g. friends, work colleagues, family, wider family, neighbours). The project consistently emerged as an ice-breaker for conversations and a community builder.

About a boy had been chosen at short notice - a quick decision had been needed if a book was to be turned into a bespoke edition in time for despatch to the students. Having assessed all the ways in which the scheme was being monitored, from its impact on student engagement to surveys of all involved, it was decided to run it again, bringing to the fore the challenge of how best to choose a shared book.

Choosing a book to be read by the entire community of domestic and international freshers, at both undergraduate and Masters level, as well as all the staff who want to be part of the scheme, is a difficult requirement. The main objectives of the scheme are to promote engagement and inclusion. As it was important that The KU Big Read project felt owned across the institution, there was a strong desire to involve the full community in book selection. It was felt that the common book should be able to draw the community together and emphasise shared humanity, not that it should nestle close to any particular discipline. It was quickly concluded that while choosing a title that would please everyone would be impossible, the project should aim to find a book that could be read with interest by all, and provoke discussion. 
Time however was pressing. If the scheme was to operate annually (as do all such established university pre-arrival shared reading schemes) then the need to choose a book would also roll around very quickly. The questionnaire sent to students and staff had asked for suggested titles and while it was encouraging that this was yielding suggestions, no one was able to put their life - or job - on hold to read and objectively appraise every suggestion made. This paper charts the process of trying to establish the best way of choosing a book, and the eventual choice made.

\section{Literature Review}

Pre-arrival shared reading of a single book is not uncommon within US universities, but associated analysis in the published literature is hard to find. It would appear that most universities site such schemes within marketing and communications and thus outcomes are generally described rather than academically analysed. For our literature search we thus explored both the literature relating to such US schemes, in both universities and civic programmes, and literature relating to book groups in general.

According to the University of Wisconsin-Madison, a shared reading scheme aims to 'engage the campus community and beyond in an academically focused reading experience; generate vigorous discussions and exchanges of diverse ideas; promote connections among students, faculty, staff, alumni, and the wider community; tap into and promote the intellectual resources of the campus; promote educational initiatives and learning outcomes; and bridge learning experiences inside and outside the classroom.' (University of Wisconsin-Madison, 2014).

Similar objectives are noted by those establishing civic shared reading schemes. The first 'One City One Book' initiative took place in Seattle in 1998 and the coordinator, Nancy Pearl, commented that it was important to 'Keep in mind that this is a library program, it's not an exercise in civics, it's not intended to have literature cure the racial divide. This is about a work of literature.' (Rogers 2002, p.16). Pearl did however subsequently refer to the role of such schemes in breaking down isolation: 'people can go for days at a time not talking to anyone outside their immediate family. There are precious few opportunities for people of different ethnic background, economic levels or ages to sit down together and discuss ideas that are important to them; this project provides that opportunity.' (At Your Library, 2012) Another early initiative was the 1998 hosting by the Washington Centre for the Book of an event with author Russell Banks, prompting country-wide interest in reading: 'there are now state-wide, citywide, countywide, and event country-wide reading programs all over the world.' (One Book, One Community [OBOC], 2003, p.4).

\section{Choosing a book for university shared reading}

Michael Ferguson comments that 'common reading programs of all types are helping bridge divides on campus: between disciplines, between student life and academic affairs, between the orientation period and the first semester' (Ferguson, 2006, p.10). How the book is chosen may however vary.

In his study of US colleges, Ferguson (2006, p.8) suggested that 'many campuses pick books that enable discussion of US and global diversity'. As an example he cited Albion College using a novel in their Common Read to 'begin student understanding of differences' and 'provide an entry for students into the ideas of global citizenship'; building on Pearl's suggestion that shared reading can encourage common ground between those from diverse backgrounds. He quotes Levine Laufgraben of Temple University, and author of Common reading Programs: Going Beyond the Book (2006), thinking that well planned such programmes signal both 'the importance of reading in college and of 'discussion and respect for diverse viewpoints.' 
How to promote understanding of contemporary diversity is an issue that has been addressed elsewhere, for example Stephen Moss (2000) cites Caryl Phillips who argues that "the "mongrel" nation that is Britain is still struggling to find a way to stare into the mirror and accept the ebb and flow of history that has produced this fortuitously diverse condition'; he believes that a novelist such as Zadie Smith, who writes about the diaspora and multiculturalism in the UK, can help understanding and promote greater society unity. Relating this to a book choice, it can be suggested that a chosen book should be one that will promote collegiality through enabling discussion, offering a story that is diverse, yet embodies the culture of the country in which it is being read. Encouraging awareness of diversity was a particularly important factor for Kingston, the most diverse university in the UK with a student population that includes 150+ different nationalities, has had a long term commitment to inclusion, adding social value and transforming life chances, and the work of Associate Professor Annie Hughes at Kingston (Hughes, 2015, 2016) on promoting transition and addressing the needs of commuting students is particularly important in this context.

The university was the 2017 winner of The Guardian's University Award for Teaching Excellence, receiving specific praise for the inclusivity and accessibility of its courses.

In addition to promoting diversity, Ferguson also suggests that using themes like 'fitting in' and 'rites of passage' can help students connect because they too are going through huge change in their lives, entering a different environment from high school which may also involve leaving home. For mature learners getting back in the classroom can be a particular challenge (ORA Prep, 2014) and the experience of shared reading can help create a community they feel part of, particularly if the book is one they can relate to.

Lehman (cited in Tienda 2013, p.468) suggests that while a diverse student body provides the necessary conditions for leveraging associated educational benefits, 'diversity does not guarantee the socially legitimate goal of integration'. Haring-Smith's findings (cited in Tienda 2013, p.470) from researching an American university that had a high level of diversity within the student body commented that the human tendency is to 'sort into islands of comfortable consensus' and concluded that rather 'integration must be deliberately cultivated through interactions that engage the diverse life experiences of students from different racial, geographic, religious, and political backgrounds.' (Tienda 2013, p.470).

Other methods of book selection emerge; some that involve students and others that are developed for them, without their involvement. For example, at Gustavus Adolphus College in Minnesota the book is 'selected the year before by a panel made up of faculty, staff, and students.' (Twiton, 2007). Washington State University (2015) however wants to (create) 'a common academic ground', and the book is chosen by the university. They do not specify who is involved in the choosing, but there is no mention of a student contribution; those taking part include 'students' professors, residence hall staff, librarians, and others lend ideas and actions to bring to life topics raised in the book' (Washington State University, 2015).

Many universities offer students paid work, for example in the campus restaurants and shops, and there is potential for using this model to involve them in choosing a book for shared reading. There is however the associated issue of whether paying students might compromise the integrity of involvement; perhaps appropriate recompense might therefore come in the form of book vouchers, to maintain the link to reading for pleasure.

R. Mark Hall (2003, p.659) concluded that universal reading schemes are not meant to be an 'academic task', rather 'aimed instead at self-help and healing' and providing a 'cultural uplift' (ibid, p.655). Hall supports the idea of making such schemes more fun than academic; establishing a more welcoming environment and providing a sense of community. At Kingston, in encouraging students 
to get involved in the selection process, the activity was suggested as being both fun and useful CV material. A quantifiable involvement in the project was made eligible as a contribution for students' Kingston Award, a scheme for recording and acknowledging individuals' contribution to the university beyond their academic studies (The Kingston Award, 2012).

\section{How the book is used}

In the literature there was general agreement that related events should be used to garner student involvement with the program, but how the book is used may link to the route through which it is chosen. Some universities use the book as part of an academic, year-long programme; others focus mainly on reading events for orientation and enrolment. A book chosen for academic gain may prompt engagement through academic formats. Otterbein College for example fully integrates the book into required first-year courses (Otterbein University, 2015), relating the experience to their year-long reading scheme and requiring students to write an associated essay. Ball State University meanwhile uses more informal means such as online forums to promote student discussion (Ferguson 2006, p.9).

Gustavus Adolphus College gives the book out to be read during the summer, and generally organises their associated events as part of orientation, focussing on the community/welcome aspect of the shared read, for example, hosting a meeting with the author as part of finalising the choice. Ferguson (2006, p.10) explores the benefits of both routes, and in particular 'programs that end when orientation ends risk leaving some students wondering why they were assigned the reading in the first place'. He also warns of 'tacking on' events to orientation, and believes that the events that take place must feel properly integrated into other orientation activities. If the event seems 'incidental', he argues, then students with struggle to connect with it.

Year-long associated programmes can however struggle to keep the discussion flowing, and the question is then posed as to how to be creative enough to keep the interest of the students, especially when they have other commitments like their graded work, sport and part-time employment (increasingly common). Kate Porubcansky, Director of the Center for Student Involvement at Otterbein University (cited in Ferguson, 2006, p.10) argues that, if a year-long route is chosen, then it must have the following: a theme that is able to sustain year-long discussion; must not overwhelm, but must be a bit of a challenge for the participants; and must be able to be used in 'different disciplinary contexts'. She also believes the scheme cannot work without university, campus and faculty support.

If a book is integrated as an academic element of the student programme there may be consideration of whether or not it should be compulsory. In this context a study by Rogers (2002) found that encouraging tutorial attendance at university did not improve performance at an Australian university. While Rodgers found a strong positive association between attendance and academic performance, both in the presence and absence of this scheme, there was no evidence that the incentive scheme caused student performance to improve. While it can be argued that students who feel included and connected to the university may feel more inclined to attend lectures/tutorials, which could lead to better marks, it may be doubted whether a book that feels irrelevant to the course selected would benefit from being made a compulsory read.

Summarising the various routes through which a book may be discussed, Levine Laufgraben (cited in Ferguson 2006, p.9) comments:

'...activities like small-group discussion satisfy "the desire to have an academic component to orientation," which often otherwise focuses exclusively on student life." In this sense, common reading programs - even when they exist solely as part of 
orientation - can give students an early taste of academic life and set the tone for the first year of college.'

'...[leaving] decisions about how a book will be used to individual faculty members has the advantage of being easy to implement. It is most likely to be effective when campuses offer discussion guides or workshops to help faculty integrate the common reading into their classes.'

'The danger of relying upon individual classes to extend discussion of the common reading is that, from the student's perspective, such an approach may appear uncoordinated. Colleen Boff, the librarian for Bowling Green State University's First Year Experience, notes that this approach creates "potential for redundancy" between classes; it also leaves open the possibility that some students will never encounter the reading again after orientation.'

\section{Making information available on a university shared read}

One Book, One Community (OBOC, 2003) recommended that planning for a reading scheme should be at least six months, if not longer; 'many communities have begun the planning process over a year in advance of the campaign launch.' (OBOC 2003, p.8) and their guide offers an intensive section on timing and planning the run up to the actual launch to ensure overall goals are met. It is suggested that a strong level of participation comes from understanding both target audience and goals, and that 'general promotional materials such as flyers, press releases, and advertisements are great vehicles for reaching a general audience of mixed ages and backgrounds.' (OBOC 2003, p.25).

For promotion, successful reading schemes often use social media, such as Twitter, Facebook, blogging platforms and well-developed websites, with plenty of information and resources. The University of Wisconsin-Madison (2014) website features a 'Marketing Toolkit' to encourage people who are keen to be involved to print off posters and offers other marketing tools to encourage word of mouth and spread involvement. Word-of-mouth (including social media) is a particularly effective form of marketing for such programmes because often one of the key institutional goals is to get discussions started. This relates to an early finding of The KU Big Read (Baverstock et al, 2016) that high levels of project discussion were evident, even among those who had not read the associated book.

Drawing on civic involvement in shared reading, Peggy Barber and Linda Wallace consider:

... that associated 'marketing is...

- about listening - not just telling or selling. It is two-way communication.

- about them - not us. We build our collections and services based on what our community/school/university/business wants and needs.

- about people - not stuff. We can't just reel off a list of our impressive inventory and expect anyone to care. (Barber and Wallace, 2010, p.1)

They found that (ibid, p.39) 'Just a question [about a scheme or program] can create more interest in programs' and that the public learned about their library schemes through 'library staff or neighbours and friends, [which] demonstrates the power of word-of-mouth marketing in the community.' (ibid, p.42).

Both OBOC and Barber and Wallace discuss ways of drawing an audience in; the latter using case studies of various libraries involving 'e-newsletters' and 'clever name[s] and logo[s]' (Barber and 
Wallace, 2010, p.55 and p.49) to demonstrate the value of word-of-mouth campaigning. OBOC (2003) go into more detail on the associated practicalities, arguing that a successful campaign comes through effective planning and utilising all possible resources. One of their suggestions is to capitalise on the fact many people will be interested in such a scheme, and undoubtedly would love the chance to help out: 'these groups, and others, can also assist with promotion by passing information on to members of their organization through newsletters, meetings, emails, posting flyers, and more.' (OBOC, 2003, p.25) They also list the key options and tips for marketing (OBOC 2003, p.26 and p.28).

In the UK while anecdotal information was gained on other universities undertaking sectional prearrival shared reading, associated analysis was hard to find. Examples included UEA offering final year students the opportunity to choose a book for addition to the pre-arrival reading of the next first year cohort. ${ }^{1}$ The University of Hertfordshire's 'Common Reading Experience' (2015) is 'focused on first-year students', although they encourage existing students to get involved too. On their website, they use their partnership with the University of North Carolina, Wilmington, to promote their reading scheme, a model that could be copied by other universities that have international exchange partners. There are also opportunities for UK universities to benefit from the activities of the Man Booker Foundation whose university initiative:

'encourages first year students at universities across the UK to appreciate and engage with the very best contemporary literary fiction. Regardless of their chosen field of study, students are given a winning or shortlisted Man Booker Prize novel to read and discuss followed by a visit from the author who takes part in a combination of workshops, lectures and reading groups.

The initiative was launched in 2009 and has expanded year on year. Participating universities have seen visits from: Julian Barnes; Sebastian Barry; Jim Crace; Karen Joy Fowler; Linda Grant; Kazuo Ishiguro; Lloyd Jones; Andrea Levy; Deborah Levy; Stephen Kelman; Hilary Mantel; Yann Martel; Hisham Matar; Simon Mawer; A.D. Miller; D B C Pierre; Ali Smith and Sarah Waters. The scheme is jointly funded by the Booker Prize Foundation and the individual universities.' http://themanbookerprize.com/foundation

Looking at the literature relating to reading groups in wider society, Barstow $(2003, p .1)$ considers how reading has come back into fashion, with many book groups being created and the associated revival of reading as a social activity, especially with the organisation of communal reading schemes within cities. She suggests revived popularity may relate to reading as a shared activity, drawing together a people of various interests through a variety of group formats such as (e.g. online, newspaper-sponsored, library-sponsored, neighbourhood, work-based, parent-child and all male groups). She found that most adults' 'non-work related reading today is done in one of three places on commuter trains and buses, in vacation settings, or at home'. In his history of reading, Alberto Manguel highlights the role of books in providing access to those with similar lives, ...'the readers, like imaginative archaeologists, burrow their way through the official literature in order to rescue from between the lines the presence of their fellow outcasts, to find mirrors for themselves in the stories...' (Manguel, 1997, p.233). Martha Nussbaum (cited in Barstow 2003, p10) argues that we should value reading of novels precisely because it often leads to emotional involvement in the lives of fictional characters, and therefore promotes empathy and compassion. But the tight focus of her focus group would imply that women from similar socioeconomic, cultural and educational backgrounds differ very little in what they see in the same text, and their interpretations reflect shared expectations that exist prior to the act of reading. Rehberg Sedo (2003) explored gendered

\footnotetext{
${ }^{1}$ Private conversation with Professor Jon Cook of UEA, November 2016
} 
reading, citing genre literature as often attracting very clear divisions in terms of male and female reading preferences.

The Oprah Winfrey Book Club (1996 onwards) attracted huge attention, and discussion of the book choices is similarly relevant. For example, Janice Radway comments:

'Oprah is obviously a serious reader, with particular goals and interests in mind. She's criticized by high-art critics or even cultural-studies scholars, because they say when she picks a book like Beloved, she's not looking at its aesthetic complexity -- she's making it sentimental, confessional. That seems like a pointless criticism to me. When you write a book and put it out, that book can be read in many ways by many different people. People are always thumbing their noses at women's reading. It's a dismissal of women's engagement with literature, rather than recognizing that it's a particular and very vital way of making literature a part of daily life. (Radway cited in Rooney, 2005, p.60).

Both the basis for book choice and their interpretation by media and viewers are examined in detail by Ted Striphas (2003).

In their detailed study of the operation of reading groups, based on contact with 350 UK book groups, Hartley and Turvey (Hartley, 2002) devote a chapter to how titles are chosen. A variety of considerations are highlighted, from the format in which work is available to the particular age, experience, and preferences of group members, including how best to achieve what Margaret Forster refers to in her foreword (p.ix) as 'stimulation by a spirited exchange of views'. One particular issue however underpins the whole chapter: how to manage and reflect responsibility for book choice; whether it is the desire of members to assume personal responsibility; to share responsibility within the group (whether through acknowledged contribution or anonymously), or delegate it to an external organisation such as media provision for such groups, in print and broadcast forms. The BBC launched their Big Read in 2003 , asking members of the public to nominate their best loved novel of all time, leading to lobbying and voting on what were announced to be the most popular choices. In all 750,000 votes were received.

The Richard and Judy television programme launched a book club in 2004, making it clear that the choices were the result of associated wide reading by the team's production and presentation team, and were not based on suggestions made by publishers or bestseller lists. The resulting lists regularly featured surprising choices (which often went on to be bestsellers having been highlighted by the programme). In the process they brought new people into reading, and expanded the horizons of those who were already active participants. Baverstock (2011) commented:

....coverage of books on Richard \& Judy won the 2006 HarperCollins Award for Expanding the Book Market (Bookseller, 2006) and an Observer poll voted Amanda Ross the most important figure in British publishing (McCrum, 2006). The trade press repeatedly reported the 'transforming' effect of their selections on subsequent sales (Bookseller, 2004). As Category Manager in charge of buying books for Tesco, David Cooke recognised the impact of Richard \& Judy:

'They have brought different books to new people. Probably $50-60 \%$ of all the books they have chosen we wouldn't have listed otherwise. The typical Tesco book buyer only buys one or two books a year, driven by covers and what's very popular.'

(Cooke, 2008) 
Kingston also accessed informal feedback from universities which had organised shared reading, interviewing participants and observers. Based on their experience, the Kingston team were warned to avoid book choices that indicated self-interest (e.g. a memoir by a key figure within the hierarchy of a university running such a scheme had been badly received). They were similarly warned against books 'emerging' from unknown selection processes; it was stressed that transparency of book choosing process and evident potential for cross-organisational involvement would promote wider engagement. When it was later proposed that the choice of a book should lie with the academic department most used to analysing literature, that they should curate a choice for the institution as a whole, discussion centred on whether routine analysis of literature made such a department super-qualified for the job of choosing on behalf of their colleagues - or did their experience debar them from choosing something that everyone would enjoy? An associated implication that reading enjoyment was owned by one department rather than widely shared was thought unlikely to enhance the project and the offer was resisted.

Another significant issue, particularly given that the first shared title had come from a Kingston graduate, was whether the book choice henceforth be Kingston-linked. In addition to the esteemed work of institutional colleagues (e.g. Adam Baron, Rachel Cusk, Hanif Kureshi), Kingston is home to many writers (e.g. Chris Cleave, Mary Lawson, Jacqueline Wilson) some of whom also set their work in the borough. While this would create an initial link with Kingston, it was thought that in the long run this might limit the choice available. It was rather decided to draw from the widest range of writers, and then seek to create strong links between the selected author and Kingston.

There were also the specific interests of the project's research partners at Edinburgh Napier to be considered. In order to be able to compare processes and outcomes, it was intended that the same book would be chosen for both locations, and so a range of authors and settings, including some in Scotland, would likely be appreciated.

\section{Methodology}

The team (comprising the Project Director, an analyst, the Project Manager and eight SADRAS students ${ }^{2}$ plus some input from KU IT department) had to develop a method for choosing a book, incorporating the learnings from the literature review. Other considerations to be taken into account when choosing the book were:

- the importance of involving the whole community in book selection, since one of the key objectives of the Big Read is to promote engagement and inclusion

- the need for the book to provoke sufficient interest to be read and discussed by a very wide community of domestic and international undergraduate and postgraduate freshers and staff at two universities

- the requirement for the method chosen to be relatively quick, as there is only a short time available between receiving survey feedback after one Big Read and preparing for publication of a bespoke edition of the next book to be ready in time for despatch to staff and students

- the need for the method to be as objective as possible, at least for deriving the shortlist of books which would then be read by the representative panel of readers, which we thought

\footnotetext{
${ }^{2}$ Previous papers (Baverstock 2016 and 2017) have outlined the original process through which The KU Big Read was developed, working with students on a SADRAS action research project.
} 
would consist of $16-20$ individuals

The method developed therefore followed the five steps outlined below, described in more detail in the following sections.

1. Finalise a long-list of books comprising all the books suggested to The Big Read project by staff and students

2. Determine the key criteria for a suitable Big Read book against which each of the books should be assessed

3. Determine a scoring system for each of the criteria and assign weights to each criterion

4. Score each book against each of the criteria to produce a weighted total score for the book. Produce a ranked list of all the books based on this scoring. Test the sensitivity of the ranking to various weighting systems

5. Pick the shortlist - the top six books on the list - to be read by the panel. Approach the publishers, and provided the publishers' responses were encouraging ask the panel members to read each of the books on the shortlist. Hold panel meetings to select the final book.

\section{Step 1: Finalise the long-list}

One of the questions asked in the student and staff surveys conducted after the first KU Big Read included an option to suggest a book or type of book for next time. In total 95 books were suggested - and this became the core of the long-list. Interestingly students were more likely to suggest classics while staff were more likely to suggest modern books. The books were wide-ranging, there were very few books suggested by more than one person and just one book (Mark Haddon's The Curious Incident of the Dog in the Night Time) was suggested by both a student and a member of staff.

\section{Step 2: Determine the key criteria against which each book should be assessed}

Bearing in mind the learnings from the literature and the considerations listed above the team agreed that the following points were important in the selection of a title for shared reading:

\section{(i) An author able to attend}

There was a strong desire for the author of the chosen title to come and speak in person about their book; it was anticipated that an author visit would give students additional impetus to read the title and engage early with their university; promoting both enrolment and engagement. As one member of the research team commented:

'I personally was more engaged with About a Boy as I knew about Nick Hornby visiting the university. I wanted to find more out about the famous author and hear his thoughts firsthand and to make sure I would fully benefit from the visit, I read the book.'

\section{(ii) Author diversity}

Kingston University is one of the most diverse in the world; the student and staff body includes representatives from over 150 different nationalities with a considerable population of international students. As this research project is a continuation of Kingston's SADRAS scheme, a diverse range of authors and reading material was considered important. SADRAS seeks to promote engagement, inclusion and a sense of community right across the institution, particularly within segments of the 
student community which have often not found transition to higher education easy, for example BME and mature students, commuters and those from a care background/with care responsibilities.

\section{(iii) A well-known author}

It was thought that featuring a well-known author would help enhance project credibility and community engagement, particularly when appealing across the institution to all disciplines and roles, including those who do not read or buy books on a regular basis. It was thought that selecting a book by a well-known author, who was either already familiar to potential participants or could be shown to be well established in their writing career, would also increase the external profile of the project, drawing attention to the university as a whole, with the potential to support application and retention rates.

\section{(iv) Author bibliography: an author with several titles available}

The choice of an established author would also increase the likelihood of their having several titles available, in addition to the one selected. This was considered important for two reasons. Firstly an author with a backlist available increases the opportunity for participants to extend their reading journey and try other titles by the same author. Secondly wider title availability supports the motivation of the participating publisher to offer a good unit price on the chosen title, on the basis that a wider 'halo effect' will benefit other work (although this presupposes that the author's backlist is all published by the same house, which is not always the case). In 2015, feedback from both student and staff surveys confirmed that participants had gone on to read other titles by the featured author; Penguin reported incremental sales on Hornby's other titles, and at the author's first Kingston event a related book stall run by a local retailer did good business.

\section{(v) Date published}

Date of publication was considered important to the chosen title's overall appropriateness, in order to secure a book that first-time students would find appealing. Some aspects of About a boy, published in 1998, were considered rather out-dated (e.g. policies around wellbeing of children have changed; there were no references to mobile phones). It was thought that some students might not become immersed in a text if they could not relate to the main character or events.

\section{(vi) Currency of title (time in which the story is set)}

Similarly, and based on prior research among the student cohort of 2014 and further discussion within the research group, it was felt that a modern setting would resonate more with incoming students, with a fear that, as a group member explained: 'a historical novel runs the risk of appealing only to those that are interested in history/the relevant period of history; a book set in more modern times may have a broader appeal.' Along similar lines, a memoir which included references to music and events the students would not recognise might perhaps be less appealing to them. Books describing years from 2000 onwards were viewed more positively as they were within the living memory of students involved.

\section{(vii) Page Count}

The physical size of the book was considered critically important; there should be no initial reaction from those receiving the book that it was either too long or difficult to read, and in particular that it would be not easy to hold and carry around. Students coming to university for the first time would want a book that is easy (and not too heavy) to take with them, and also one that doesn't look like a chore to read during their holidays. It was decided that the optimum extent would be 250-350 pages but a shorter book would be preferable to a long one. As regards the actual page size, variation between publishers and their standard paperback sizes was allowed for.

\section{(viii) Gender-neutral cover}


A gender-neutral cover was thought desirable, meaning one that is 'suitable for, or applicable to, or common to both male and female genders' ${ }^{3}$ in the hope that, on first impression, both men and women would be equally drawn to consider reading the book, whether they were spotting it through the polylope mailing package, or picking it up in person from the university.

Consideration of what is gender-neutral is however necessarily subjective; depending on an individual's conception of gender-neutrality and influenced by both conscious and unconscious bias. There are simplistic mechanisms that can be applied, for example avoiding too much pink or stereotypically masculine imagery unless specifically relevant to the plot. It was also considered that gender neutrality should be evident in the words used on the cover as well as the images chosen, so the font, gender of endorsers and language of the book blurb all needed to be considered. It was however important to retain balance, and a cover that reflected the story contained, thus Jackie Kay's Red Dust Road, which featured a picture of a small girl, was included on the shortlist as various aspects of the design made it clear that this was a memoir rather than a specifically female read.

A possible way around these difficulties was to revert to publishers' previous packaging of specific titles; often the hardback had a more gender-neutral cover than the paperback. It was eventually decided however that consistency was important and therefore it was best to review the current paperback for each title. Another solution was to create a cover specifically for Kingston, perhaps involving students from Kingston University's Art School to design one for the university. This was decided against for two reasons, firstly because it would significantly slow the process down and secondly because it was thought important for students to see that a real book had been purchased for them that was also available in shops, enhancing their perception of an item they were being given for nothing.

\section{(ix) Genre}

The appeal of genre titles was also considered; this had featured in the pre-project research of 2014 when the findings had shown that the specific appeal of fantasy, science fiction (collectively often known as 'genre titles') as well as romance and thrillers had all drawn lower support than a more mainstream title that might appeal more broadly across the community. While it was acknowledged that it was probably impossible to find a book that everyone would like, consideration of the genre would potentially reduce the risk of students being discouraged from reading the book due to preconceived notions about whether or not they already liked such material. ${ }^{4}$ The research group concluded that a genre title might be an alienating choice for a shared reading project aimed at a large group of people with different backgrounds, tastes, and levels of reading for leisure.

\section{(x) Location of plot}

There was discussion as to whether a Kingston University Big Read should be set in the UK in order to instil a sense of geographical familiarity in the arrivals, whether they were home students (EU or UK) or international.

Reading a book set in a location that will shortly become home can has the potential to create a sense of connection with the student. An international member of the SADRAS team commented that the 2015 choice had done just that, and she had:

'found it both beneficial and exciting to be reading a story set in my new home. The book acted as a surrogate friend, welcoming me to my new city, the characters and their experiences helping my transition to life in London.'

\footnotetext{
${ }^{3}$ www.Oxforddictionaries.com

${ }_{4}^{4}$ Philip Pullman has commented that his Dark Materials Trilogy is for 'fantasy people who don't like fantasy'.
} 


\section{(xi) Reviews}

It was generally agreed that the chosen title should above all be a good read. But again this has the disadvantage of being a subjective criterion, with discussion about whether this meant it should be critically acclaimed or widely enjoyed. Amazon reviews were selected as the basis for establishing this criterion. Reviews are not entirely reliable - there is a risk they may be written by friends and relations of the author - but it was felt that this was still the most feasible method of gauging the general likeability of a book without requiring each title to be read by a member of the research team. The wide number of those reading and reviewing on Amazon means the sample size was large, and it was decided to focus on the 'average customer review' star rating that Amazon provides. While a high review on Amazon is not a guarantee of a good book a poor review was perhaps an indicator of an unsuitable book.

\section{(xii) School curriculum}

There was a desire not have a book that had featured on the UK school curriculum as it was therefore likely to be familiar to a significant proportion of the potential readers who, even if they had not read it, might feel a resistance to an 'approved title'; this drawing on research by Penguin into the meaning of their brand as 'books I was forced to read at school'. ${ }^{5}$ As one member of the research team commented:

'We did not want awaiting students to feel like this was part of their course and a recommended reading task. By excluding any titles that have been, or will be, studied, it gives the scheme more of an appeal and seems less of a chore.'

\section{(xiii) A 'general comments' section}

It was felt that some issues relating to book selection were too indistinct to be predicted or itemised, but nevertheless important to observe. A 'general comments' section was therefore included in the selection criteria, allowing the opportunity to note any additional issues that the more obvious criteria did not attend to, for example areas of difficulty that we felt were inappropriate for 18 year olds' first move away from home or the specific issues of our student demograph. A book was sought that could be the basis of an ice-breaking conversation; for this to be sufficiently deep to motivate conversation but without becoming too controversial, sad, dark or depressive.

\section{Step 3: Determine a scoring system for each of the criteria, and then a weighting system}

Having agreed on the most important criteria the next step was to assign a scoring system for each one. We noted that the scores should be normalised so that the maximum possible score for each criterion was the same, and decided on a maximum of 5 . We then assigned rules for each criterion. For example for page count the scoring system was 5 points for a book of optimum length (considered to be 250-350) 4 points for a slightly shorter book (150-249 pages). 3 points for 351-400 pages, 2 points for under 150 pages and 1 point for more than 400 pages as this was considered dauntingly long for the purpose. Similarly the Reviews criterion was scored using the Amazon star rating rounded to the nearest point.

The next challenge was to derive a weighting system for the criteria. Following the group discussions about which were criteria were the most important, each of the 11 team members drew up their own weighting system such that the weights for each of the thirteen criteria totalled $100 \%$. These were then averaged and the average weights used for the final ranking. Partly for team interest and partly to test sensitivity we also looked at which books would have been chosen under each individual's weighting system to see how much they varied.

\footnotetext{
${ }^{5}$ Personal conversation between lead author and Andrew Welham, Marketing Director and Deputy Managing Director, Penguin Books
} 
The most important criteria according to the average weighting were whether the author could attend, the page count, the gender neutral cover, the genre and the author's diversity, while the least important was the author's bibliography.

Step 4: Score each book against each of the criteria and calculate a weighted score. Rank the books then test the sensitivity.

The Project Manager then undertook extensive desk research in order to look up the required data (page length, Amazon review, publication date, author information, location etc.) for each book to be able to score it against each of the criteria. An example (though with the titles excluded) is shown below. The weighting scheme was then applied to each of the individual scores so that a weighted score could be calculated for each book.

The books were then ranked in order of their weighted scores so that the top six could be identified. Nick Hornby's About a Boy was included in the coding process (though obviously it wouldn't be considered again for this year) to see where it would come in the ranking. Interestingly it came $5^{\text {th }}$ overall and so would have been in the shortlist.

For interest and in order to test the sensitivity of the weighting system we also looked at the top six books that would have been selected using each team member's individual weightings. For the most part the same five books would have surfaced to the top (though the order might have varied). The sixth book however would not have been on everyone's list. As it happens the book that was eventually chosen scored either first or second on ten out of the eleven individual weightings.

Step 5: Approach the publishers of the top six books. Ask all panel members to read the books.
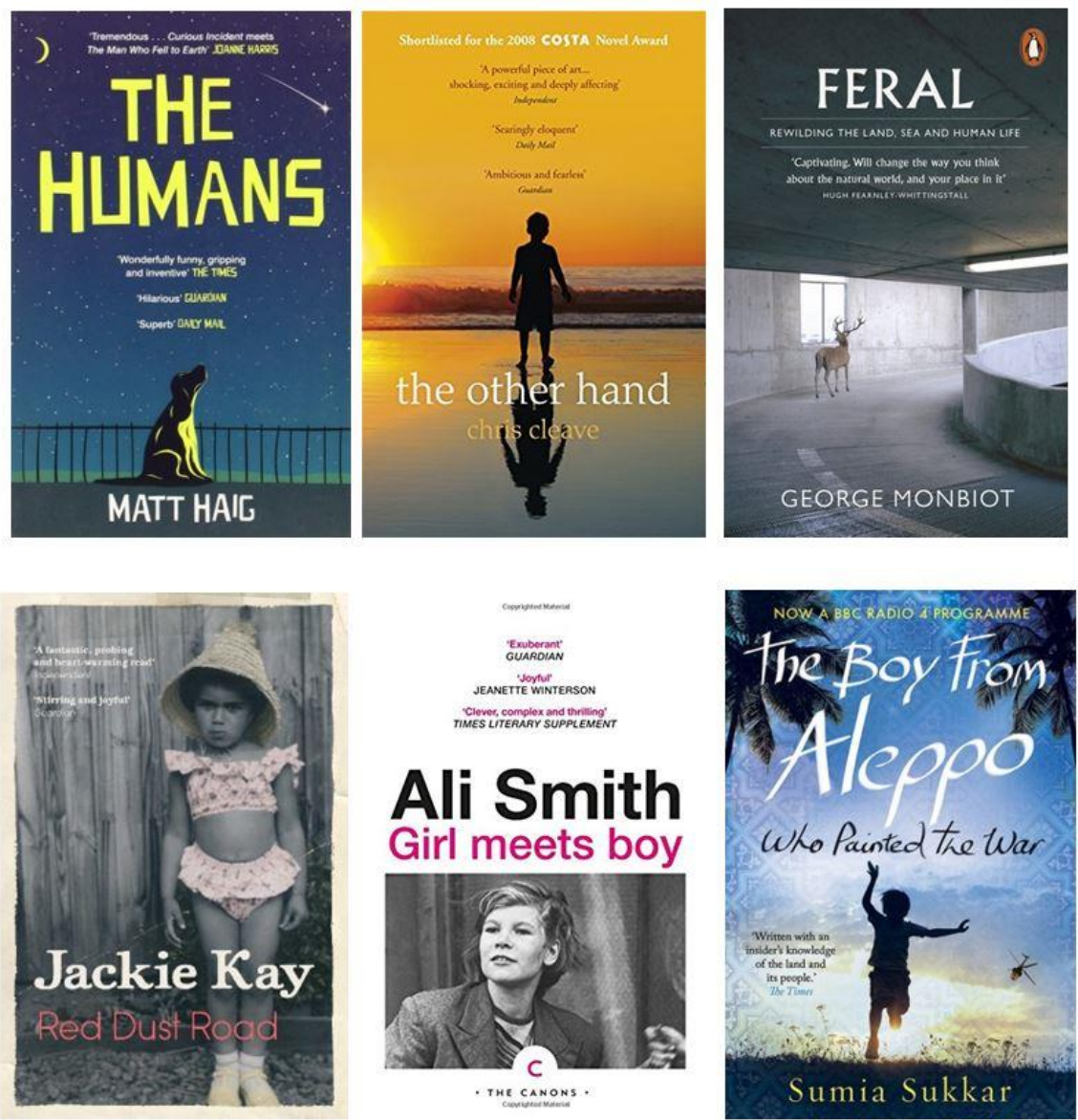
The emerging shortlist for the second iteration of The KU Big Read was a balanced in author gender (three men, three women); included fiction and non-fiction, a diverse range of titles and author backgrounds and was from a range of different publishers (two large, two middle sized and two very small). Two of the books were published by Edinburgh firm Canongate (Ali Smith and Matt Haig), and two of the authors were Scottish (Ali Smith and Jackie Kay).

\section{Involving the relevant publishers}

The six publishing houses of the shortlist titles were written to, informed of the project, how the shortlist of books had been arrived at and that one of them was from their list. They were asked to give speedy consideration to three issues:

1. Was their author was available for participation; willing to come and talk at both Kingston and Edinburgh?

2. Were they willing to collaborate on the creation of a special edition of the book and make it available to the university at a competitive rate? No figures were mentioned and it was specifically indicated that while a competitive rate was hoped for, the full author royalty would be paid.

3. In which case, if they would make available 20 free copies of the book to distribute to the judges (although in the case of the smallest two publishers, Kingston offered to pay for the stock).

The six publishers responded variously, one very enthusiastically by return of email, one soon afterwards in similar vein, including quoted enthusiastic response from the author, one over two weeks later after having been chased many times and contact had been made with the author to try to prompt action. 20 copies of each book for distribution among the selection panel were requested, and in the case of the independent publishers, payment was offered. The publisher that had replied late about whether or not their author could be included had to be repeatedly chased for the books, which eventually arrived on the morning of the photoshoot.

The shortlist was announced on $1^{\text {st }}$ February 2016 via the Vice Chancellor's monthly letter to staff, and having been secretly bought and catalogued, copies of the shortlisted titles were made available the available the same day to students and staff through prominently placed spinners in libraries across the university, with the titles featured in the student press, local and social media. There was strong interest in the displays, particularly after they appeared on the digital screens across the institution. A third of library staff (34) read the entire shortlist and there was widespread discussion of the titles:

'You have really created a buzz. I feel I must read the shortlist.' Dr Shereen Nabhani-Gebara, Senior Lecturer, Pharmacy 


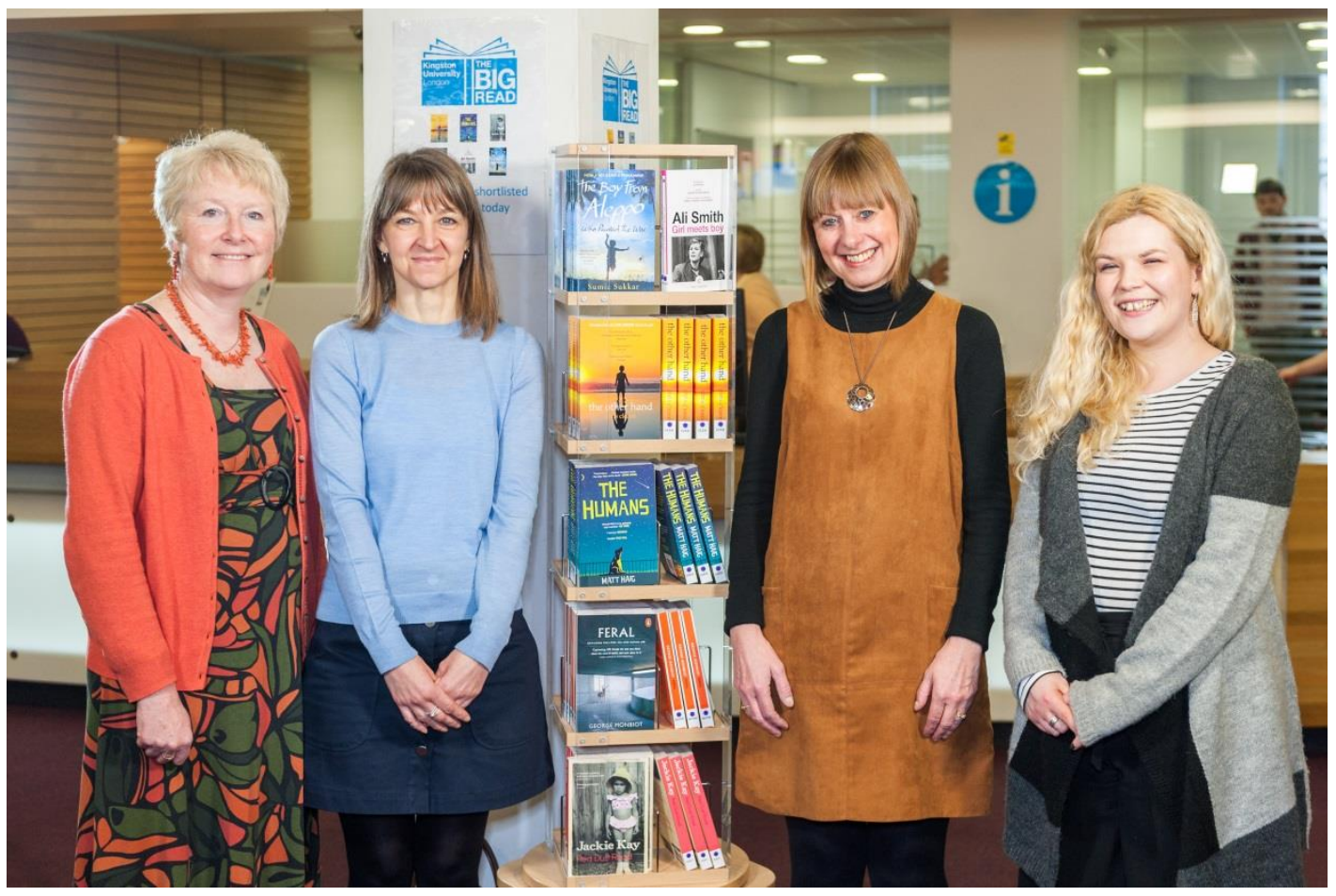

Image 2: A spinner showing the stock bought by the library to support wider reading of the shortlist within the community. Left to right: Project Director Alison Baverstock, Kingston librarians Wendy Woodley and Wendy Morris, Project Administrator Laura Bryars.

\section{Selection panel}

The six books on the shortlist were then read by a panel composed of people already recruited from throughout the university including four students (a mixture of undergraduate and Masters), the Vice Chancellor, a research coordinator, a receptionist, an academic, a technical demonstrator and a librarian. Particular care was taken to ensure a cross-institutional group that included a range of roles, ethnicities, ages and professional seniorities. Presentations were made within a variety of forums, student and staff, to secure broad involvement. In the case of faculties or role not represented after the initial trawl, specific approaches were made via university hierarchies asking for representation. Overall, enthusiasm to take part was high and a list of those wanting to participate in future years was begun.

All were given their books in February, and had two months in which to read them before meeting twice to talk about the final choice. Staff from Edinburgh Napier were represented on the panel and took a full part in both representing their recommendations and voting. 


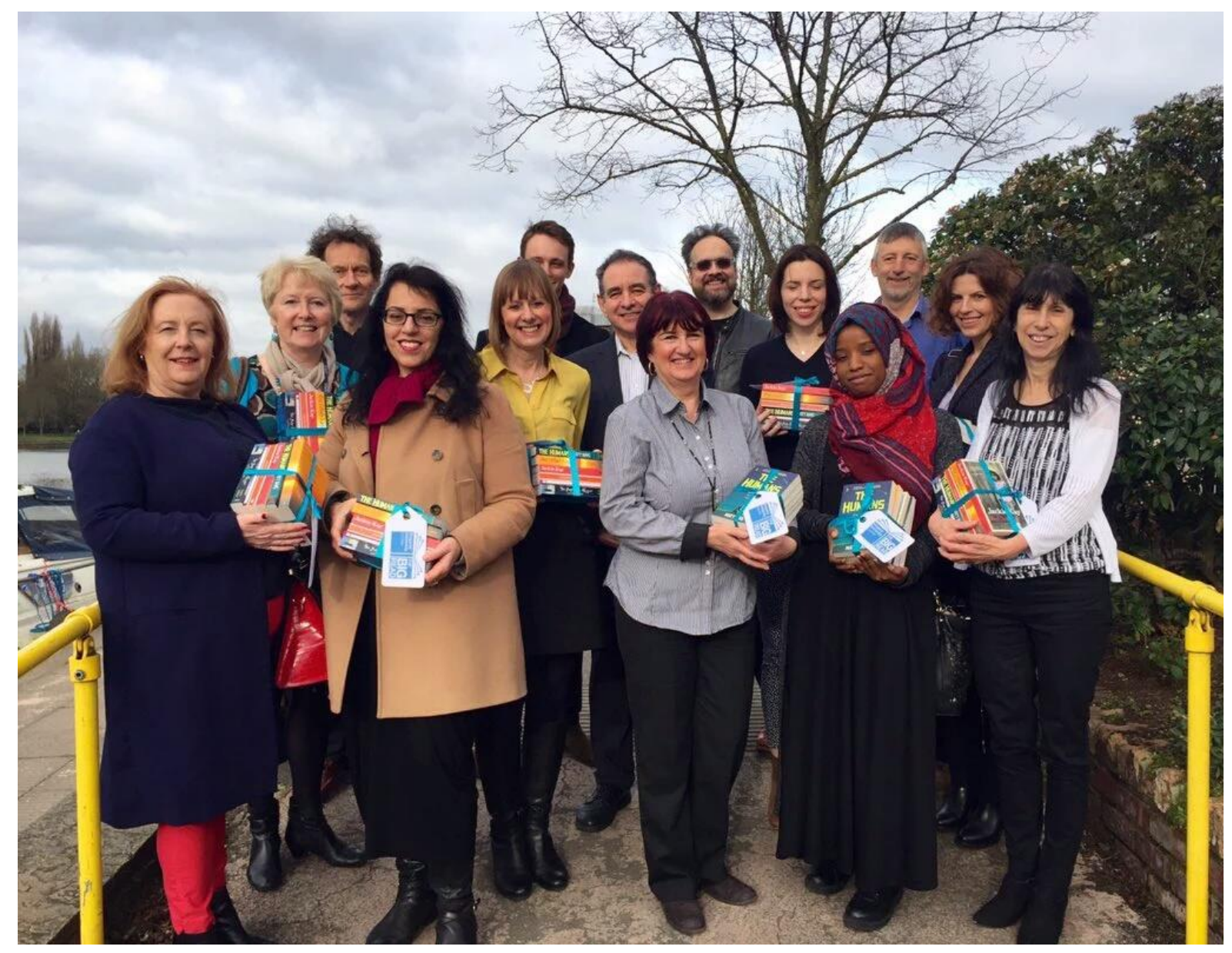

Image 3: the selection panel for The KU Big Read 2016

\section{Progress of selection meetings}

Two meetings were held to discuss the shortlist of six titles, both from 5-7pm. An open discussion was encouraged with everyone invited to participate; it was particularly important to ensure the student voice was heard, given that the majority of the group consisted of staff - albeit from a wide range of roles. Refreshments were provided to encourage an informal atmosphere. The first panel meeting was chaired by the VC and before the second there were discussions about how to get everyone, and in particular the students, to contribute more.

\section{Features of the discussion}

In a paper featuring the work of six esteemed writers, it would not be politic to feature discussion relating to individual titles. But for a wider understanding of associated processes, and what was learned, the following may be helpful.

1. Before the first meeting, six individuals were asked to speak briefly about one of the books on the shortlist, highlighting positive and negative points. They were specifically not allocated a book that they had nominated themselves.

2. The chair began by reminding all present that the task in hand was to choose what would make the best Kingston University Big Read; a title that could hopefully be read with interest and enjoyment across the institution and form the basis of discussion. They were asked to 
note that this was not an exercise in literary criticism, to find the 'best' book, rather to find the title most likely to offer the best basis for shared reading and discussion.

3. Before the meeting started, the chair asked each panel member to note down their preferred order of titles. This was put to one side. They were then asked to revisit their choices at the end of the first meeting and the scores were kept by the group secretary. During the second meeting voter averaging was looked at, without the public noting of associated names. There was discussion about whether a book that scored highly but was no one's first choice would be as good a vehicle for discussion as one that had a mixture of scores, some very positive, others much less so.

4. A note was taken of the order in which individual members of the group had read the titles. It was found that individuals had thought about the order in which to read their allocated books, although different methodologies had been used. Some group members had begun with those that attracted them most (for various reasons), others had been aware of their preferences but used deferred gratification as their means of deciding which title to read first, saving the one they most wanted until last.

5. The appearance of the cover was held to impact on reading intentions. One title was several times mentioned as being approached with caution, but then really enjoyed.

6. Regular votes were taken, and at the end of the first meeting two titles were dropped from the shortlist with four to be presented at the second meeting. Four people (not those who had presented previously) were asked to offer short summaries of these titles to the second meeting.

7. There was a lengthy discussion about whether the demographics of the author of last year's book (white male) should influence the 2016 choice. The project was initially envisaged as a support for student engagement and retention, but had proven very popular with staff; whereas student recipients would be unaware of the previous choice, staff would.

8. Two books had specific connections to Kingston and their relevance was discussed at some length; perhaps setting a precedent that in the longer term only a Kingston-connected author could be chosen.

9. The period of time in which the book was set was explored in some detail. While the currency of the plot might not date, perhaps music and television references might not be caught by students. Alternatively, given the current taste of younger generations for things retro - e.g. vintage clothes and vinyl records - this might be viewed as an unnecessary sensitivity.

10. The author's likely proficiency as a speaker was considered. It was hoped for an author who was eager to be involved, could relate to the students and inspire them.

\section{Conclusion and learnings for next time}

In the end, although a close run thing, Matt Haig's The Humans was the unanimous choice of the second meeting. The title was announced in mid-April 2016 and institutional response to the announcement was very positive. Events connected with the book were held in September/October and feedback on the book was mostly very favourable. The shortlist had offered a diverse range of potential authors, and types of publishing house, but the emergence of a second white male as victor did draw comment, and lead to consideration that weighting of the criterion for 'author 
diversity' within the algorithm might need to be reconsidered when choosing a book for 2017.

'A wonderful author who engaged readily both online and when visiting KU. The book itself was funny and sweet and just a little bit dark. A great all-encompassing choice for such a broad range of readers. Truly accessible.' (Comment from staff survey)

Reflecting on the book choice process it was thought that:

- There are ongoing challenges endemic to the process of choosing a book for a whole institution to read. Kingston's approach was to consistently keep two key principles in mind. Firstly that the main market was the forthcoming Kingston University student, and so the needs and interests of an 18-year old about to arrive in higher education for the first time should be of primary concern to those making the choice. Secondly that the process aimed to find not the 'best' book (whatever 'best' means) but rather one that could be read with interest by all.

- Neither the method for deriving the shortlist nor that for selecting the final book could ever be completely objective; there is judgement involved in selecting the important criteria, in setting up the scoring and weighting systems and in the final reading of the shortlist. Nonetheless the method used was a very useful basis for selecting the best book for sharing within the particular but very diverse cohort of the KUBR readers - undergraduate and postgraduate freshers, all members of administrative and academic staff, and the wider participating community - in as objective and transparent a way as possible. The algorithm had the benefit of allowing everyone to be involved in recommendations for the long-list and for this list to be narrowed down to a shortlist in a manageable amount of time using readily available data on each book and without the need for the involvement of extensive numbers of additional readers.

- The algorithm can be used each year and quickly implemented. It can be tweaked each time to incorporate learning from the experience of the previous year(s) and from the feedback surveys afterwards. For example, the book choice for the KUBR 2017 is already underway, and based on feedback from 2016 a new criterion has been included about the importance of the first few pages of the books under consideration, and the weightings have been tweaked to reflect comments about author diversity reflecting Kingston's highly diverse student population.

- How many panel meetings are needed? Given that the book that emerged as the community choice had been identified as the likely forerunner from the beginning of the first meeting onwards, there was post-panel discussion about whether panel processes had in fact been more complicated than necessary - certainly the original idea of having three meetings was probably offering too much time. While the rankings of the books by panel members changed relatively little between meetings, and perhaps the business could have been completed within a single meeting, it was felt appropriate to continue to allow for two panel meetings. This permitted panel members the opportunity to change their minds and to reflect afterwards on the opinions of others expressed during meetings.

- Asking panel members to consider the order in which they read the books, and their associated rationale, led to some interesting conversations. It's a good way to gauge people's attitudes to the physical qualities of the book, as they would be experienced by the intended recipient - is the cover gender neutral, is it too big/too heavy, etc.? This did however need to be discussed in the context of the reader's general tendencies, e.g. were 
they inclined to read their favourites first or to base their reading order on the prospect of deferred gratification?

- There was discussion about how to enable the student voice to come through, in both title suggestion and panel meetings, particularly given that the group contained a wide range of staff from across the institution.

- Although the eventual decision was not to select a title on the basis of the author's connection to Kingston, it is possible to create a strong link between chosen author and institution. Both Nick Hornby and Matt Haig will receive honorary degrees from Kingston in 2017.

The Kingston University Big Read is now established as part of the institution at Kingston. The associated research programme has yielded rich data for further analysis and it is intended that future papers will examine other aspects of the scheme, from its impact within certain demographies to the creation of value around an item given away without charge.

\section{BIBLIOGRAPHY}

'At Your Library'. (2012). One Book, One City. [Online] Available at: http://atyourlibrary.org/libraries/one-book-one-city [Accessed January 25, 2015].

Barber, P. and Wallace, L. K. (2010). Building a Buzz: Libraries \& Word-of-Mouth Marketing. [Online] Available at:

https://books.google.co.uk/books?id=G1J2SSoELhAC\&pg=PA47\&lpg=PA47\&dq=marketing+a+comm unity+wide+read\&source=bl\&ots=qSPYsa2VCQ\&sig=MQF4EeRUfYPjWREVXkvUdvk4gr8\&hl=en\&sa=X \&ei=03DsVNiEF4HhUo-

MgOAH\&ved=0CEcQ6AEwBg\#v=onepage\&q=marketing\%20a\%20community\%20wide\%20read\&f=fal se [Accessed January 26, 2015].

Baron, P. and Corbin, L. (2012). Student Engagement: Rhetoric and Reality. Higher Education Research and Development 31:6, pp.759-772.

Barstow, J.M. (2003). Reading in Groups: Women's Clubs and College Literature Classes. Publishing Research Quarterly Winter 2003, 18:4, pp.3-17.

Baverstock, A. (2011). How books became less 'different'. An exploration of the rise of marketing within the publishing industry $1980-2010$, and consideration of how this not only changed the business model, but impacted on the role of the author; with consideration of the likely associated implications of these developments in future. A critical appraisal to accompany a range of publications. PhD by Publication, Oxford Brookes University.

Baverstock, A. et al (2016) 'The implementation of a shared reading programme within a university: A case study'. Logos 27(2), pp.48-61.

Baverstock, A. et al (2017) 'What was the process and response of university staff and students to the availability of a shared reading scheme for those embarking on a university education? A case study.' Logos 28 (2) (in press)

Bhaskar, M. (2016). Curation, the power of selection in a world of excess. London: Piatkus.

Bookseller (2004) News item: 'The Richard and Judy effect', 1/30/2004, Issue 5113, p15-15, London: Nielsen Business Media

Cooke, D. (2009) http://news.bbc.co.uk/1/hi/magazine/8128436.stm Accessed 12 November 2010.

Ferguson, M, 2006. Creating Common Ground: Common Reading and the First Year of College. Peer Reveiw Summer 2006, 8:3, p.8-10.

Fetherston, R. L. (2007). Books as Elements of Pleasure: Establishing a University Wide Reading Program in an Oral Society in the Middle East. The International Journal of the Book. [Online]. 4(4). pp.177-184. Available at: http://ijb.cgpublisher.com/product/pub.27/prod.190 [accessed April 3, 2016]. 
Hartley, J. (2001). Reading Groups. $2^{\text {nd }}$ Edition. Oxford: Oxford University Press.

Hughes, A. (2015) Student diversity and student integration are not necessarily the same thing: an exploration into the social interaction patterns of students from a diverse range of backgrounds. HERAG Conference, 5 June 2015.

Hughes, A. and Garside, P. (2016). 'Accommodating' different ways of doing University: understanding the challenges faced by commuting students to overcome barriers and identify solutions. HEIR Conference Liverpool, 7-8 September 2016.

Kingston University. . Worldwide Exchange Partners. [Online] Available at: http://www.kingston.ac.uk/undergraduate/why-choose-kingston-university/studyabroad/worldwide-exchange-partners/> [Accessed January 25, 2015]. Lavine Laufgraben, J. (2006). Common Reading Programs: Going beyond the book. National Resource Center for First-Year Experience and Students in Transition.

Manguel, A. (1997). A history of reading. London:Harper Collins.

Mark Hall, R. 2003. The "Oprahfication" of Literacy: Reading "Oprah's Book Club". College English, 65:6, pp.646-667.

McCrum, R. (2006) 'Our top 50 players in the world of books.' The Observer. $5^{\text {th }}$ March 2006 Available from: http://www.guardian.co.uk/books/2006/mar/05/features.review Accessed 1 September 2011

One Book, One Community (OBOC). 2003. American Libray Association. [ONLINE] Available at: http://www.ala.org/programming/onebook. [Accessed 25 January 2015].

ORA Prep. (2014). A Guide to Life as a Mature Student. [Online] Available at:

http://www.oraprep.com/guide-life-mature-student/ [Accessed January 26, 2015].

Otterbein University. 2015. About Common Book. (Online) Available at:

http://www.otterbein.edu/public/Academics/EnrichmentPrograms/CommonBook/AboutCommonB ook.aspx [Accessed January 25th, 2015].

Rehberg Sedo, D. (2003) 'Readers in Reading Groups: An Online Survey of Face to Face and Online Virtual Book Clubs'Convergence' The International Journal of Research into New Media Technologies, 9:1.

Rogers, M. 2002. Libraries offer chapter and verse on citywide book clubs. Library Journal, 127:6, pp.16-18.

Rooney, K. (2005). Reading with Oprah: The Book Club that Changed America. $1^{\text {st }}$ Edition. Arkanses: The University of Arkansas Press.

Striphas, E. (2003). 'A Dialectic With the Everyday: Communication and Cultural Politics on Oprah Winfrey's Book Club', Critical Studies in Media CommunicationVol. 20, No. 3, September 2003, pp. 295-316

Tienda, M, 2013). Diversity Not Equal to Inclusion: Promoting Integration in Higher Education.

Educational Researcher, 42:9, pp.467-475.

The Guardian, Stephen Moss. 2000. 'White Teeth by Zadie Smith.' [ONLINE] Available at:

https://www.theguardian.com/books/2000/jan/26/fiction.zadiesmith. [Accessed 25 January 2015].

The Kingston Award,

https://mykingston.kingston.ac.uk/myuni/thekingstonaward/Pages/default.aspx

Twiton, A. (2007). Common Reading Programs in Higher Education. [Online]. Available at:

https://gustavus.edu/library/Pubs/Lindell2007.html [Accessed January 26, 2015].

University of Hertfordshire. (2015). Connect: The Common Reading Programme [Online] Available at: http://www.herts.ac.uk/connect/common-reading-programme [Accessed January 26, 2015].

University of Wisconsin-Madison. 2015. Go Big Read. [Online] Available at:

https://gobigread.wisc.edu/. [Accessed 26 January 2015].

Washington State University. (2015). WSU Common Reading: Overview [Online] Available at:

http://commonreading.wsu.edu/overview/ [Accessed January 26, 2015].

Wright, D. (2006). 'The Big Read: Assembling the Popular Canon.' The International Journal of the Book, 4:4, ppp19-26. 
